\title{
ESCOLA SECUNDÁRIA E FORMAÇÃO PARA O TRABALHO NA ARGENTINA: POLÍTICAS E SABERES EM DISPUTA
}

\author{
ESCUELA SECUNDARIA Y FORMACIÓN PARA EL TRABAJO EN ARGENTINA: \\ POLÍTICAS Y SABERES EN DISPUTA
}

\section{SECONDARY SCHOOL AND WORK FORMATION IN ARGENTINA: POLICIES AND KNOWLEDGE IN DISPUTE}

\author{
Silvia MARTINEZ \\ Delfina GARINO ${ }^{2}$ \\ Natalia FERNANDEZ ${ }^{3}$
}

\begin{abstract}
RESUMO: Este artigo tem como objetivo analisar as relações entre políticas educativas e propostas de formação para o trabalho em escolas secundárias de Neuquén (Argentina), colocando em diálogo normativas e dispositivos didático-pedagógicos que implementam as instituições, desde uma perspectiva que considera as políticas como um campo de disputas tanto em sua definição, como em sua colocação em ato nas escolas. Para isso, relevamos normativas sobre propostas pedagógicas situadas em contextos de trabalho e analisamos, desde metodologias qualitativas, sua colocação em ato em escolas secundárias centradas na formação para o trabalho. Logo da análise, propomos que as vinculações com as normativas são diversas (às vezes as práticas educativas as antecipam e outras as escolas dão respostas parciais a elas), e as formas de implementação podem favorecer ou não a democratização da participação de estudantes (e com isso a distribuição equitativa de saberes), assim como concepções sobre mundo do trabalho, sociedade e sujeito.
\end{abstract}

PALAVRAS-CHAVE: Escola secundária. Formação para o trabalho. Saberes. Política educativa.

RESUMEN: Este artículo tiene como objetivo analizar las relaciones entre politicas educativas y propuestas de formación para el trabajo en escuelas secundarias de Neuquén (Argentina), poniendo en diálogo normativas y dispositivos didáctico-pedagógicos que implementan las instituciones, desde una perspectiva que considera las políticas como un campo de disputas tanto en su definición, como en su puesta en acto en las escuelas. Para

\footnotetext{
${ }^{1}$ Instituto Patagónico de Estudios de Humanidades y Ciencias Sociales (IPEHCS-CONICET-UNCo); Facultad de Ciencias de la Educación, Universidad Nacional del Comahue (FACE-UNCo), Neuquén - Argentina. Professora Adjunta Regular do Departamento Didático. ORCID: https://orcid.org/0000-0001-8473-9934. E-mail: silviamarcelamartinez@gmail.com

${ }^{2}$ Instituto Patagónico de Estudios de Humanidades y Ciencias Sociales (IPEHCS-CONICET-UNCo); Facultad de Ciencias de la Educación, Universidad Nacional del Comahue (FACE-UNCo), Neuquén - Argentina. Chefe de Trabalhos Práticos do Departamento de Ciências Políticas e Sociais. ORCID: https://orcid.org/0000-00020320-8830. E-mail: delgarino@gmail.com

3 Facultad de Ciencias de la Educación, Universidad Nacional del Comahue (FACE-UNCo), Neuquén Argentina. Primeiro Assessor do Departamento de Política. ORCID: https://orcid.org/0000-0002-2551-058X. Email: natinoefernandez@gmail.com
} 
ello, relevamos normativas sobre propuestas pedagógicas situadas en contextos de trabajo y analizamos, desde metodologías cualitativas, su puesta en acto en escuelas secundarias centradas en la formación para el trabajo. Luego del análisis, planteamos que las vinculaciones con las normativas son diversas (a veces las prácticas educativas las anticipan y otras las escuelas dan respuestas parciales a ellas), y las formas de implementación pueden favorecer o no la democratización de la participación de estudiantes (y con ello la distribución equitativa de saberes), así como concepciones sobre mundo del trabajo, sociedad y sujeto.

PALABRAS CLAVE: Escuela secundaria. Formación para el trabajo. Saberes. Política educativa.

ABSTRACT: This article aims to analyze the relationships between educational policies and work formation in secondary schools in Neuquén (Argentina), connecting regulations and didactic-pedagogical devices that are implemented in educational institutions. In order to do this, we consider policies as a dispute field, in its definition, as well as in its implementation in schools. To achieve our goal, we review regulations focalized in work formation and analyze, using qualitative methodologies, their implementation in secondary schools. After analysis, we propose that linkages between practices and regulations are diverse (sometimes educational practices anticipate regulations and other times schools give partial answers to them), and the ways of implementation may or may not contribute the democratization of student participation (and consequently an equitable distribution of knowledge), as well as conceptions about the world of work, society and subject.

KEYWORDS: Secondary school. Work formation. Knowledge. Educational policy.

\section{Introdução}

Na América Latina, as sociedades apresentam mudanças profundas no mundo laboral e educativo nestas últimas décadas. Observa-se que nas sociedades latino-americanas os processos de inclusão no campo laboral são delimitados, se aprofunda a precariedade laboral e o desemprego (especialmente para os/as jovens). No entanto, no campo educativo há uma ampliação da cobertura nos diferentes níveis do sistema educativo. Ou seja, estamos diante de um declínio do mercado laboral e uma expansão do educativo, processos segundo os quais se oferecem aos/as jovens poucas opções de trabalho para habilitá-los à sustentação dentro do sistema educativo (ainda que mediado pelas dimensões como a classe, o gênero e a raça, muitos/as conseguem ao menos cursar e/ou finalizar o nível secundário ${ }^{4}$, situação impensada 50 anos atrás).

${ }^{4}$ Por ejemplo, el aumento de la tasa de escolarización de los/as jóvenes de 15-17 años en América latina entre el 2005 y el 2013 se incrementó del 72,5\% al 76,6\%, superando en 2013 el umbral del 78\% de jóvenes en edad escolar dentro de la escuela secundaria en Brasil, Argentina, Chile, Ecuador, México, Perú y Uruguay (Montes, 2018). 
Nos interessou este panorama para pensar no lugar da escola secundária no geral e na sua relação com o mundo do trabalho em particular. Nos centramos na Argentina, onde, no começo do novo século, se sancionaram duas leis importantes em matéria educativa: a Lei de Educação Nacional $\mathrm{N}^{\circ} 26.206$ (LEN), em que se propõe a obrigatoriedade da escola secundária e propõe que este nível prepara para seguir estudando, para o trabalho e a cidadania; e a Lei da Educação Técnico Profissional №26.058 (LETP), que legisla especificamente sobre a educação técnico profissional, pautando especificidades sobre os vínculos com o mundo laboral, entre outros aspectos.

Portanto, estas legislações de 2006 e 2005, respectivamente, regulamentam sobre um sistema educativo nacional, fragmentado em um estado federal. Assim, cobra-se a importância de estudar casos particulares que não refletem o panorama do país, mas dão conta dos modos em que as instituições resolvem a relação escola-mundo do trabalho.

Nos focamos neste texto a analisar as articulações sobre a educação e o trabalho que se dão em uma província da Norpatagônia Argentina: Neuquén. Esta província apresenta níveis de autonomia em relação à legislação nacional, sendo uma mostra disso a não aplicação da Lei Federal de Educação de 1993, a partir de uma legislação provincial. Com respeito à LEN de 2006, que propõe uma reforma da escola secundária, atualmente se encontra em plena construção e implementação de um currículo inovador, elaborado desde as bases de todas as escolas secundárias e suas diferentes modalidades (bacharel, comercial e técnica).

Este artigo se inscreve no marco das investigações que abordam a relação entre educação e trabalho na escola secundária (BARROS; COSTA-RENDERS, 2020; ANDRADE MARTINS，2018; JACINTO，2018; CORROCHANO， 2014; GOROSTIAGA，2012). Colocamos em foco as Práticas Profissionalizantes (PP), dispositivos privilegiados que as legislações nacionais e provinciais propõe para a relação educação e trabalho, e nos modos em que as instituições propõe aos mesmos. Nos centramos, concretamente, nas PP e em sua regulação através das normativas vigentes, sua implementação em escolas selecionadas, assim como na concepção do mundo do trabalho e os saberes que promovem.

Como se trabalhará as maneiras de implementar as PP são diversas, e supõe a introdução de saberes do mundo do trabalho na implementação de projetos pedagógicos que costumam ser valorados pelos/as estudantes:

A evidência empírica de investigação na Argentina e outros países mostra que a introdução projetos pedagógicos vinculados aos saberes do trabalho geram maior motivação e interesse nos jovens. Os processos de aprendizagem que partem de saberes práticos para desde ali propor saberes 
teóricos, ou que se conhece como o valor pedagógico da formação orientada e da aprendizagem situada (JACINTO, 2018, p. 87).

$\mathrm{Na}$ argentina, os estágios em âmbito de trabalho (como uma modalidade atual de PP) foram o dispositivo que historicamente visibilizava a relação entre teoria e prática. No entanto, as normativas sancionadas desde inícios deste século ampliaram a concepção destas práticas, instalando a figura das PP. Neste sentido, antigamente os estágios eram pensados como um agregado prático da formação teórica, pelo contrário, as PP se propõe como uma estratégia para o ensino de teorias, técnicas formais e habilidades de maneira contextualizada (DURSI, 2016), tanto em empresas como em outras instituições da sociedade civil, do estado e dentro das próprias escolas.

Além disso, as PP são parte fundamental dentro da trajetória formativa dos/as estudantes de escolas secundárias técnicas e se propõe como síntese da articulação entre a teoria e a prática a partir de experiências formativas em situações reais de trabalho, os quais podem ter diferentes formatos: micro empreendimentos, projetos produtivos, articulação com demandas da comunidade, estágios, etc.

Cabe destacar que as PP são obrigatórias para todos/as os/as estudantes de escolas técnicas, e optativas para os/as estudantes de escolas comuns, de maneira tal que nos últimos anos passou de um dispositivo de formação para o trabalho seletivo, a um tipo de prática que deve garantir a participação de todos/as, de maneira que, esta mudança na sua concepção e legislação aparece como uma democratização das mesmas. Claro está, como desenvolveremos na continuação, que a implementação das PP supõe uma posta em ato da normativa que as regula, e a maneira em que se executam apresenta especificidades conforme as instituições, que em alguns casos superam o proposto pela legislação, em outros não alcançam para cobrir seus orçamentos, mas sempre tensionam e disputam normativas.

O objetivo deste estudo é abordar as práticas pedagógicas que articulam educação e trabalho em três escolas secundárias com características diferentes. Nossa análise se focaliza na implementação destes dispositivos de formação para o trabalho e a relação com as normativas nacionais, sua concepção do mundo do trabalho e os tipos de saberes que promovem. Desta maneira, nos registramos nos debates que analisam os sentidos da escola secundária em geral, olhando a transmissão cultural que se propõe nos dispositivos vinculados com o trabalho, ao mesmo tempo em que os sentidos que propõe esta experiencia escolar quando está articulado através do trabalho.

$\mathrm{O}$ artigo se estrutura em seis seções, na primeira, desenvolvemos o marco teórico metodológico que enquadra as análises desenvolvidas; na segunda abordamos a normativa 
que rege a implementação de PP a nível nacional e provincial; na terceira, descrevemos a implementação das PP em três escolas secundárias da província de Neuquén; na quarta, comparamos a implementação das PP nas três instituições; por último, apresentamos as considerações finais do artigo.

\section{Marco teórico-metodológico}

\section{Aspectos teóricos}

Abordamos este estudo em duas dimensões, portanto, tomaremos marcos teóricos que vão se articulando e permitindo abordagens específicas. Por um lado, o relativo à dimensão político-normativa, que inclui as normativas nacionais e provinciais, ou seja, as políticas públicas criadas desde o Estado. Por outro lado, a dimensão pedagógico-didática, que considera a implementação de dispositivos de formação para o trabalho em escolas secundárias desde as vozes de professores e diretivos implicados. Cabe esclarecer que entendemos os dispositivos antes mencionados como promotores de experiências pedagógicodidáticas enquadradas ou não em políticas públicas, que buscam aproximar os/as jovens do mundo de trabalho.

Em relação à dimensão político-normativa, partimos de considerar que as relações sociais se articulam no Estado. Os resultantes das relações de poder entre os/as atores se institucionalizam nas políticas públicas, normas, programas e linhas de ação (AGUILAR VILLANUEVA, 1993). Assim, as lutas de poder estão na base das políticas públicas e encaminham para a definição de pautas de ação.

Por outra parte, reconhecemos a distância que existe entre o âmbito de circulação do discurso (nacional, local) através do texto político (normativa, legislação) com o da prática; onde os mesmos são re-significados e re-contextualizados pelos atores institucionais (BALL et al., 2012). A colocação em ato se constitui como campo no que se definem essas intenções e interesses e se materializam os acordos de maneira concreta (BALL et al., 2012). Estes acordos são sempre transitórios, mas habilitam o desdobramento de práticas que deixam marcas nos sujeitos que transitam nestas realidades.

Neste artigo, nos focalizamos nas PP desde um olhar das políticas públicas e das múltiplas mediações que se manifestam em sua implementação, como estratégia para analisar, desde uma dimensão pedagógico-didática, a vinculação da educação secundária com o mundo do trabalho. O desenvolvimento destas práticas supõe a articulação de atores do 
mundo da educação, do mundo do trabalho e da sociedade civil (do sistema educativo, das escolas, do mundo empresarial, ONGs, atores estatais e, certamente, os/as jovens), que disputam a construção de sentidos e a maneira em que estas práticas se implementam. Dado que estes atores têm objetivos de ação e se regem por lógicas específicas, as relações entre atores que se estabelecem costumam estar atravessadas por tensões, (JACINTO, 2016).

$\mathrm{Ou}$ seja, tomamos a estas PP como dispositivos que articulam um conjunto de atividades pedagógicas que se integram e combinam intencionalmente para facilitar uma aprendizagem (CAMILLIONI, 2014). Nos interessa tanto compreender a configuração destes dispositivos como o tipo de experiências educativas que promovem. O estudo se propõe a partir de uma perspectiva teórica que tem como objeto os dispositivos de formação da investigação, enquanto estes permitem analisar os modos de articulação complexa que se estabelecem entre os discursos, as normas, as distribuições temporais e espaciais (entre outras), que dão forma a um modo de existência em um tempo e um espaço histórico determinados. Para analisar a dimensão didática retomamos as relações epistêmicas com os saberes desde Charlot (2008).

Nestes dispositivos, enfocamos a relação entre o sujeito e o saber, ou seja, o sentido do aprender que promovem. Em primeiro lugar, identificamos uma vinculação entre o sujeito e os objetos-conhecimentos, referidos a conhecimentos técnicos, disciplinares. Em segundo lugar, destacamos aquela relação que promove o saber através da ação, ou seja, o domínio de uma atividade. Em terceiro lugar, referimos situações que promovem aprendizagens sociorelacionais (CHARLOT, 2008).

A importância desta proposta estabelece que a estas vinculações se deve a construção identitária com o saber, já que aprender tem sentido em função de uma história do sujeito, seus antecedentes, suas expectativas, sua ideia da vida, seus modos de se relacionar, etc.

Nos enfocamos, então, no estudo nesta relação: normativas e dispositivos de formação propostos como PP, que em espaços da prática assumem formas concretas, nas que circulam discursos, se promovem modos de subjetivação e se geram experiencias particulares, que habilitam sentidos e modos de existência específicos.

Simultaneamente, distinguimos trabalho de emprego: este último supõe uma relação assalariada, ao contrário, o trabalho é tomado como uma condição humana desde uma perspectiva social, antropológica e filosófica, e pode implicar ou não numa remuneração (NEFFA, 2003). Este, considerado como a atividade humana dirigida à satisfação das necessidades, acarreta em si uma dimensão produtiva (no sentido de transformação da natureza e do objeto em geral) e uma dimensão formativa (na medida em que toda ação 
reverte sobre o sujeito da mesma, o transformando). Pensamos no trabalho como artesanato: "designa um impulso humano duradouro e básico, o desejo de realizar bem uma tarefa, sem mais" (SENNETT, 2009, p. 20), onde a relação mente e corpo são inseparáveis. Tomamos a Sennett (2009) quando propõe, desde uma concepção pragmática, a relação entre mente e corpo, argumentando que o que somos surge do que nosso corpo pode fazer. Continua assim argumentando sobre o impacto desta característica nas relações sociais.

Ou seja, focalizamos a análise nos dispositivos de formação para o trabalho (PP) suas articulações com as políticas e o tipo de saberes que promovem (o que e o como do mesmo), desde um olhar didático. Por sua vez, buscamos localizar os processos de contextualização e recontextualização de saberes em relação ao mundo do trabalho, já que entendemos que estes espaços formativos expressam os debates mais amplos em torno da definição da formação da escola secundária, a relação com o mundo do trabalho e a sociedade em geral.

\section{Aspectos metodológicos}

Propomos captar a complexidade do objeto de estudo desde uma perspectiva interpretativa: propomos descrever e analisar a relação entre as normativas e os dispositivos de formação para o trabalho que se realizam em três escolas ${ }^{5}$ da província de Neuquén, na Argentina.

Selecionamos estas instituições com base em uma amostragem qualitativa de casos escolhidos em função de critérios teóricos relevantes para o problema de investigação. Focalizamos na articulação com o mundo do trabalho que propõe estas escolas, a partir de dispositivos de formação para o trabalho, tanto na vinculação com o exterior das instituições, como com respeito ao objetivo educativo que propõe. A Escola $\mathbf{N}$ é uma escola secundária comum com orientação em economia social e prática de microempreendimentos, que propõe projetos inovadores de articulação com formação profissional; a Escola A é uma técnica agropecuária que propõe um projeto inovador de relação com o mundo agropecuário da região; e a Escola I é a primeira escola técnica industrial da região e se relaciona com a atividade produtiva mais importante da província (produção de petróleo e gás).

${ }^{5}$ Las escuelas que tomamos se encuentran ubicadas en la provincia de Neuquén, Norpatagonia argentina, cuya población es de alrededor de 600.000 habitantes y su matriz productiva se centra en la extracción de petróleo y gas, con fuerte demanda de trabajadores en el sector público (administración pública, educación, salud, etcétera) y en comercio. 
Desde uma metodologia qualitativa, se utilizaram diversas técnicas de coleta da informação ${ }^{6}$ a) Levantamento de fontes secundárias (normativas nacionais e provinciais referidas a dispositivos de articulação como mundo do trabalho; Projetos curriculares e institucionais); b) Entrevistas semiestruturadas (a professores e equipes diretivas das escolas); e c) Observações (de espaços de implementação de PP e de diferentes momentos da vida escolar).

Quadro 01 - Trabalho de campo realizado. 2011-2018

\begin{tabular}{|l|l|l|l|}
\hline & \multicolumn{1}{|c|}{ Escola N } & \multicolumn{1}{|c|}{ Escola A } & \multicolumn{1}{c|}{ Escola I } \\
\hline Temporalidade trabalho de campo & $2011-2016$ & $2013-2018$ & $2016-2018$ \\
\hline Projetos institucionais / programas & $\begin{array}{l}\text { PEI } \\
\text { Programas 3 }\end{array}$ & $\begin{array}{l}\text { PEI } \\
\text { PIC } \\
\text { Programas 3 }\end{array}$ & $\begin{array}{l}\text { Convênio } \\
\text { estágio }\end{array}$ \\
\hline Entrevistas a diretivos & 2 & 2 & 2 \\
\hline Entrevistas a docentes de PP & 5 & 4 & 2 \\
\hline Observações & 2 & 2 & 2 \\
\hline
\end{tabular}

Fonte: elaboração própria

\section{Dimensão político-normativa: o marco legal das PP}

As políticas educativas formuladas a meados da primeira década do século XXI postulam uma nova forma de pensar a articulação educação e trabalho na Argentina, com base em um novo modelo de relação Estado-sociedade-sistema produtivo (GALLART, 2006).

Efetivamente, durante os '90 impulsionou-se uma série de reformas educativas, nas que a visão do mundo do trabalho esteve atada a uma lógica de empregabilidade. Nesta época, se fez explicito o vínculo entre a escola e a empresa (organizações empresariais) para assumir

${ }^{6}$ Los datos de este articulo son parte de tres tesis doctorales y del proyecto de investigación C127 de la Facultad de Ciencias de la Educación-UNCo (2016-2020):

Martínez, Silvia (2016) "Dispositivos de formación para el trabajo y la experiencia escolar en la escuela secundaria técnica. Estudio de casos". Tesis de Doctorado en Educación, Facultad de Filosofía y Letras, Universidad de Buenos Aires.

Garino, Delfina (2017) "Escuela secundaria y trabajo: incidencias de los dispositivos de formación para el trabajo en las trayectorias laborales de jóvenes en la ciudad de Neuquén", Tesis de Doctorado en Ciencias Sociales, Facultad de Ciencias Sociales, Universidad de Buenos Aires.

Fernández, Natalia (en evaluación) "La puesta en acto de las políticas educativas referidas a la educación y al trabajo en el nivel secundario técnico: el papel de los actores involucrados (Estado, sector empresarial y comunidad educativa) en la Provincia de Neuquén”. Tesis (Doctorado en Educación) - Universidad Nacional del Comahue, s/d. 
o compromisso de formação nestes espaços, e os estágios foram considerados como "sacolas de emprego" diante do decreto nacional 340 de 1992.

Em 2003, começa um processo de 'reordenamento legal' (VIOR; MAS ROCHA, 2009), no qual se sanciona um conjunto importante de leis nacionais, com respeito à política educativa, das quais destacamos a Lei de Educação Técnico Profissional (LETP) (2005) e a Lei de Educação Nacional (LEN) (2006).

No que se refere à educação e ao trabalho, a LETP promove as práticas laborais através do desenvolvimento de PP. As $\mathrm{PP}^{7}$ constituem um dos quatro campos formativos da Educação Técnico Profissional (os três restantes são: formação geral, científico-tecnológico e técnica específica), onde cada campo tem uma carga horária específica. Assim, a incorporação das PP mostra que as práticas laborais se constituíram em um requisito da educação técnica (FIGARI, 2017).

Além da incorporação das PP na educação técnica, se faz extensiva a importância de práticas de trabalho, tais como os estágios na educação secundária, comuns por meio do decreto $1374(2011)^{8}$. A sanção do decreto permitiu que aquelas províncias que não tinham legislação própria pudessem aderir ao decreto ou elaborar normativas em correlação com a legislação nacional. Isso possibilitou também estimular as empresas em desenvolvimento de convênios com as jurisdições ou com as instituições educativas para a articulação de um sistema de estágios (MATURO, 2018).

Ademais, as PP como dispositivo de ensino e aprendizagem possibilitam a incorporação de hábitos e saberes que só se adquirem num marco laboral (GALLART, 2004), podem orientar aos/as jovens com relação a seus interesses e permitir o ingresso a um segmento do mercado de trabalho, o que poderia ser difícil ingressar (JACINTO; DURSI, 2010).

Com respeito ao marco político-normativo da província de Neuquén, conta com uma Lei Orgânica de Educação Provincial No 2945 (2014) que regula todo o sistema educativo. Estabelece intenções pedagógicas, fins e objetivos similares à LEN: a educação integral com igualdade de oportunidades, a garantia da inclusão educativa, o estabelecimento do Estado como garante no acesso, permanência e egresso dos/as estudantes, a integração da comunidade educativa. Como respeito ao espaço das PP, ao final de 2018, se sancionou uma

\footnotetext{
${ }^{7}$ En la resolución 261/06 del Consejo Federal de Educación (Ministerio de Educación Nacional), que tiene como fin la homologación de los títulos, se plantea fundamental su práctica y se las entiende como síntesis de la articulación entre la teoría y la práctica a partir de experiencias formativas en situaciones reales de trabajo.

${ }^{8}$ Régimen General de Pasantías que rige en todo el ámbito del Nivel de Educación Secundaria del Sistema Educativo Nacional, donde no son obligatorias para el secundario común.
} 
normativa específica provincial que as regula ${ }^{9}$ em escolas públicas e privadas, escolas comuns e técnicas.

A obrigatoriedade das PP nas escolas técnicas nos permite perguntar como são os processos de concretização que se realizam a nível jurisdicional para garantir estes trajetos formativos que podem assumir diferentes formatos (estágios, microempreendimentos, projetos dentro das instituições, etc.). Fica explícita então a concepção sobre as PP, como campo formativo dentro da ETP, que leva a reestruturação dos planos de estudo ou desenhos curriculares das províncias, em busca de garanti-las.

Se identificam algumas questões transversais que entendemos podem afetar a "posta em ação” das PP (MATURO; FERNÁNDEZ; GANEM; SAEZ, 2018): a juventude dos marcos normativos provinciais em relação com os nacionais, a importância da mediação institucional e o estímulo e acompanhamento à geração de acordos a nível local.

Na jurisdição de Neuquén, se evidencia um movimento instituinte que parece tracionar desde as instituições escolares técnicas para a norma e desde a norma para as instituições e destacamos que, entre os principais desafios da colocação em prática do espaço de PP, figuram como é a geração de convênios com empresas, organizações civis (no âmbito público, como privado), como é a mediação institucional na participação e a execução de convênios por parte de órgãos de governo na gestão de vinculações com organizações produtivas, comunitárias, etc.

Tal como afirma Rodrigo (2017), muitas vezes a aplicação dos marcos normativos descansa e se sustenta nas desiguais capacidades de gestão das jurisdições e instituições. Neste sentido, é importante continuar com a análise sobre como as instituições educativas se vinculam em concreto com a formação para o trabalho no marco das demandas atuais das novas normas do setor produtivo e da sociedade.

\section{Dimensão pedagógico-didática: a implementação das PP}

Neste artigo, analisamos 3 escolas secundárias da província de Neuquén, das quais, duas se encontram na cidade de Neuquén (capital provincial), e a terceira numa localidade vizinha. Cabe destacar que esta região da Província aglutina $66 \%$ da população. A continuação, descrevemos cada instituição, nos enfocando em seus dispositivos de formação para o trabalho.

${ }^{9}$ Resolución $\mathrm{N}^{\circ} 1862$ sancionada por el Consejo Provincial de Educación de la provincia de Neuquén. 


\section{Escola N: caracterização geral da instituição}

O primeiro caso que apresentaremos é a Escola $\mathbf{N}$, uma escola secundária pública de gestão privada (depende da diocese de Neuquén), de 5 anos de duração, que concede o título de Bacharel especializado em Economia Social e Práticas de Empreendimentos que articula com oficinas de formação profissional em Desenhos construtivos, Informática, Agropecuária ou Gastronomia. Criada em 2005, tem uma matrícula de 250 estudantes aproximadamente, metade homens e metade mulheres, provenientes de lares de baixos recursos materiais. Se encontra em uma região semirrural da cidade de Neuquén, composta por bairros que se iniciaram como assentamentos informais, com serviços deficitários, tenências da terra precárias e pouca frequência na circulação do transporte público de passageiros.

No plano curricular, propõe que durante o $1^{\circ}$ e o $2^{\circ}$ ano todos/as os/as estudantes alternam pelas quatro oficinas ao longo do ano e, no $3^{\circ}$, escolhem uma delas, na qual se especializam até o $5^{\circ}$ ano. Além disso, a partir do $3^{\circ}$ ano, oferecem matérias da orientação da escola (Economia Social, Contabilidade, Teoria de Microempreendimento, Prática de Microempreendimento).

\section{Formação para o trabalho na Escola N: autonomia e construção de um projeto vital como eixo da proposta}

A formação para o trabalho está no centro da proposta educativa e implica na capacitação tanto em saberes gerais para o mundo do trabalho (modelos econômicos, direito laboral, condições do mercado de trabalho), como em dispositivos específicos de formação para o trabalho (JACINTO, 2018).

Um desses dispositivos são os empreendimentos produtivos que se realizam nas quatro oficinas, são pensados como espaços de formação e como práticas reais de trabalho, enquadradas em atividades impulsionadas desde a própria instituição, que propicia a formação contextualizada, vinculando a escola com o mundo exterior.

Para catering temos tudo, a louça, toalhas de mesa, toucas, aventais, o traje é bom, montamos toda uma instalação na escola para fazê-lo, e os meninos [...] aniversários de 15, casamentos, de tudo fazem com a professora. [...] Isso implica todo um movimento na escola, [...] todo um entrelaçamento, mas dá bons resultados (Professor 1, Escola N).

Para isto, no $3^{\circ}$ ano, todos/as os/as estudantes escrevem em grupos um projeto de microempreendimento, que executam durante o $4^{\circ}$ e o $5^{\circ}$ ano. Além disso, cada fim de ano a 
instituição realiza uma exposição aberta à comunidade onde se mostram e se comercializam os produtos realizados nos empreendimentos.

Outro dispositivo se refere à orientação laboral e à implementação de estágios: durante o $5^{\circ}$ ano, os/as professores entrevistam jovens para projetar suas trajetórias (educativas e/ou laborais) posteriores ao egresso. Em função deste processo, se implementam estágios para todos/as os/as alunos, que são planificados e atribuídos em função de seus interesses vocacionais.

Há uma entrevista pautada que se faz com os meninos. E, em função disso, [...] vão se buscando com os conhecidos que temos, com experiências anteriores. [...] É a medida, em função dos interesses de cada menino, se pensa em que possibilidades temos de fazer, que, onde e com o que contamos... (Equipe Diretiva, Escola N).

Tem por objetivo, além de que conheçam espaços de inserção em campos de interesse, ser experiências em relação de dependência acompanhadas, assim como ampliar o capital social dos/as jovens. Neste sentido, se promovem experiencias situadas que permitem aprendizagens na ação (CHARLOT, 2008). Se designa um docente encarregado/a de planificá-las e acompanhá-las. No entanto, o cargo es ad honorem, o qual implica numa precarização da tarefa que, somado a que muitos dos contatos com as organizações, empresas e instituições que recebem estagiários dependem de vínculos pessoais (não institucionais), gera uma baixa institucionalização de alguns aspectos desta prática.

Finalmente, outro dispositivo é o ditado de cursos especiais orientados ao mundo do trabalho, que busca ampliar a formação com a contribuição de especialistas em diversas áreas, enquadrados nas orientações da escola. Se desenvolvem durante três semanas localizadas no fechamento de cada trimestre, nas que se suspende a atividade acadêmica cotidiana e os/as estudantes do $4^{\circ}$ e $5^{\circ}$ ano realizam oficinas de capacitação para o trabalho. A oferta de cursos varia de ano a ano, conforme os/as especialistas que se contatam, e a disponibilidade de fundos para financiar as atividades (que, por sua vez, depende da obtenção de recursos especiais através de projetos financiados por organismos públicos).

Ademais, a orientação da escola em Economia social favorece a formação de sujeitos críticos com respeito às condições do mercado laboral, capacitando e desenvolvendo efetivamente formas de organização social e laboral alternativas às hegemônicas vinculadas ao capitalismo. 


\section{Escola A: caracterização geral da instituição}

A segunda instituição selecionada é a Escola A. É uma escola agrotécnica de 6 anos de duração que possui um prédio de 26 hectares onde desenvolve suas atividades. Em suas origens (1987), buscava articular com o setor agropecuário (a temporalidade da escola acompanhada a do agro, tinham prioridade os filhos de fazendeiros, etc.), mas depois a escola se incluiu dentro do sistema educativo formal, se adequando às normas vigentes (1996). Conta com 400 estudantes (50\% homens; 50\% mulheres), heterogêneos/as tanto em suas características socioculturais, como em sua procedência.

O plano curricular se estrutura em quatro áreas: disciplinar, produção animal/vegetal e espaços institucionais ${ }^{10}$. Os espaços disciplinares estão presentes durante toda a formação, do $1^{\mathrm{o}}$ ao $4^{\mathrm{o}}$ ano os/as alunos/as conhecem produções animais e vegetais e realizam práticas e, no $5^{\circ}$ ano, escolhem uma das duas orientações (vegetal ou animal). Em ambas orientações, no $6^{\circ}$ ano, cursam Seminários e as matérias Projeto Didático Produtivo e Estágio ou Extensão.

\section{Formação para o trabalho na Escola A: ensino articulado desde o produzir}

Esta escola propõe aprender desde o produzir. Seus dispositivos de formação para o trabalho vão armando uma rede de sentidos e significados que permitem diferentes tipos de aprendizagens.

O primeiro dispositivo é o Projeto Didático Produtivo. No $5^{\circ}$ ano, todos/as os/as alunos/as em grupos formulam um plano de produção (investigam, realizam as previsões), articulando distintas matérias (Língua, Metodologia de Projetos, Projeto Didático Produtivo, Inglês) e, durante o $6^{\circ}$ ano, o executam. Cabe destacar que os/as estudantes escolhem o tema de seus projetos e supõe um trabalho pedagógico.

Finalizando o $4^{\circ}$, escolhem um projeto de uma produção em particular. Por grupo de três a cinco pessoas. (...) No $5^{\circ}$ formulam, fazem toda a investigação. Porque lhes pedem todo o método científico, tudo para formular o projeto produtivo dessa produção (...). Em socio-economia aprendem todo o econômico, que tem a ver com investimentos. No $6^{\circ}$ ano, com fundos da escola, conforme a aprovação do projeto do $5^{\circ}$, se executa aqui na escola. Então temos que comprar galinhas, arame, tudo isso para armar o projeto (Equipe Diretiva, Escola A).

${ }^{10}$ En este curriculum a lo largo de los 6 años tienen espacios obligatorios de participación y acompañamiento a la escolaridad, como espacios de convivencia escolar. 
Esta situação se dá no marco de uma atividade didática regulada e pautada; simultaneamente, se poderia dizer que é uma situação simulada, já que se realiza dentro da escola, a diferença do que seria um empreendimento real.

A proposta que sustenta o plano curricular em relação com o Projeto Didático Produtivo e as maneiras em que os diferentes sujeitos o vão cruzando, erigem a este dispositivo como síntese do projeto institucional. Destacam-se os valores de responsabilidade, trabalho, organização e trabalho em equipe, e muitos/as destacam este espaço como transcendente na construção de aprendizagens com sentidos para os/as estudantes, que implica na participação em todas as etapas de um projeto produtivo: planificação, execução, avaliação, exigindo inovações nas propostas.

Aqui temos tudo o que é da parte de formulação de projetos, que não se baseia simplesmente em armar o anteprojeto, escrevê-lo, mas sim que se deve executá-lo, lhe dar um seguimento, avaliar os resultados, chegar a um produto final... e bom, em todo esse processo se incorpora um monte de ferramentas e aprendizagens muito significativas, que depois servem para o trabalho técnico (Professor 13, Escola A).

O segundo dispositivo é o projeto de extensão rural, que é parte do currículo e quando participam todos/as os/as estudantes. Nele, se propõe diferentes momentos de trabalho que incluem a sensibilização, o diagnóstico, a proposta e, se se pode, o trabalho conjunto, desde um olhar de técnico extensionista, em que se promove interpretar uma realidade técnica em um contexto socio histórico específico e que os/as estudantes se envolvam em problemáticas da região, como, por exemplo, a construção de estufas em hortas comunitárias em bairros marginais da cidade de Neuquén.

O terceiro dispositivo são os estágios, que nesta instituição também são curriculares, participam todos/as os/as jovens e se realizam durante todo o ano. Numa primeira etapa, são estágios internos, em que os/as estudantes circulam pelos diferentes setores produtivos da escola e logo realizam estágios externos em empresas e empreendimentos da região. No caso de que não consigam articular com agentes externos à instituição, continuam com os estágios internos, nos que os/as alunos/as atuam como ajudantes em distintos setores.

Sintetizando, a intenção educativa em todos os dispositivos de formação para o trabalho está na cobrança de sentido para os/as estudantes, no fazer, no contexto real. Uma inovação no real percurso curricular dos/as estudantes é o fato de que desde o começo lhes é proposta uma articulação de saberes teóricos e práticos. Se promovem, assim, relações com o saber disciplinar, em ação e com outros/as (CHARLOT, 2008). 


\section{Escola I: caracterização geral da instituição}

A terceira instituição selecionada é a Escola I, uma escola técnica industrial tradicional de 6 anos de duração, que se encontra no centro da cidade de Neuquén e que oferece três modalidades: mecânica, eletromecânica e construções. Mantém mais de 1200 estudantes, maioritariamente homens. Criada em 1943, possui uma vasta tradição histórica.

Do $1^{\mathrm{o}}$ ao $3^{\mathrm{o}}$ ano, os/as alunos/as cursam o Ciclo Básico, comum a todas as escolas técnicas, e no Ciclo Superior $\left(5^{\circ}\right.$ e $\left.6^{\circ}\right)$ se especializam numa das três orientações, em que cursam matérias e oficinas específicas de cada uma.

\section{Formação para o trabalho na Escola I: o modelo industrial tradicional}

A formação para o trabalho atravessa toda a proposta formativa da escola e se articula especialmente em matérias teóricas e nas oficinas. Além disso, a instituição implementa estágios como um dispositivo de formação para o trabalho.

Este projeto está em vigência faz mais de dez anos, principalmente em empresas privadas cujas atividades se vinculam às orientações da escola, no setor hidrocarborífero, automotriz, etc. Nestas praticas, os/as estudantes aplicam, desenvolvem e aprofundam saberes das especialidades que cursam. Para isto, uma professora realiza as monitorias aos/as estudantes que estão nas empresas, ocupando um cargo ad honorem, já que a escola não conta com horas específicas para financiar o trabalho que supõe este projeto, portanto, fica a "vontade" da professora de manter o espaço.

O que passa é que, bom, aqui existe algo particular. Se eu não faço, isto cai, se ninguém quer fazer porque não é pago, e eu posso mais o compromisso que tenho com isso de fazer, ou seja, sou professora, parte da minha responsabilidade civil em ensinar é isto também (Professora 1, Escola I).

Ademais, este projeto não está destinado a todos os estudantes e não são obrigatórios, mais sim entram um número limitado de estudantes em função da quantidade de convênios conseguidos e do número de vagas em cada empresa.

Nos focamos nos conteúdos, na atitude do menino, aptidão também e na vontade com que se trabalha, como se desempenha, como interatua com o resto, como é para trabalhar em grupo (Professora 1, Escola I).

Efetivamente, a escassez de instituições receptoras deriva em que os/as estudantes devam reunir certas condições para ingressar e permanecer no lugar, que inclui certas aptidões e habilidades vinculadas com os requerimentos do mundo do trabalho: a importância da 
aquisição de certos saberes técnicos para "aplicá-los" na prática, assim como a necessidade de certas habilidades e capacidades vinculadas ao atitudinal (responsabilidade, pontualidade, trabalho em equipe). Se propõe que estes requisitos são sintetizados nas qualificações dos/as jovens nas matérias, de maneira que os/as estagiários/as são selecionados/as em função de critérios meritocráticos. Ademais, na seleção operam pautas específicas, propostas pelas empresas (por exemplo, aspectos vinculados ao gênero). Desta maneira, a perspectiva meritocrática e individualizante governa a proposta de acesso aos estágios.

Por último, na escola existe um projeto de formação em ciclomecânica que implica no conserto de bicicletas em desuso, como estratégia para a contenção social e empoderamento dos/das jovens, desde uma perspectiva comunitária, coletiva e cooperativa, que inclui a ideia de acesso livre ao conhecimento. Em este caso, o conhecimento técnico veicula um compromisso social. É impulsionado por atores da sociedade civil, e participam os estudantes que assim o desejam.

São os espaços de encontro onde o conhecimento começa a se coletivizar e as ferramentas se dividem e, na realidade, termina sendo uma espécie de meio para outras coisas. [...] [A ideia é] que seja um espaço onde eles entendam que podem construir laços com outras pessoas desde o conhecimento técnico para um compromisso social. [...]. Fomentamos a horizontalização do conhecimento e depois que este conhecimento se dê de uma maneira livre. Esse é um pouco do objetivo, potenciar o empoderamento das pessoas, por meio do conhecimento e através de gerar espaços onde a pessoa se encontre (Referente ONG, Escola I).

Cabe destacar que, enquanto articula com a comunidade e implica formação para o trabalho, desde a normativa vigente, poderia ser considerado uma PP, mas não é lido como tal pelos atores institucionais, que só reconhecem como PP ao formato estágio. Isto dá conta de uma visão de mundo do trabalho ancorada na inserção laboral em relação de dependência. Pensando desde as relações com o saber que se promovem, estes se vinculam com ações em contexto, ao mesmo tempo em que se orientam a conhecer espaços de trabalho e os saberes sobre a sociedade que isto habilita.

\section{Perante as normativas, a institucionalização e as vontades: a democratização de saberes nas PP}

A partir do trabalhado em cada instituição, propomos comparar as propostas de implementação de PP nas escolas selecionadas, tomando como critério a ideia de democratização de experiências, que permite alcançar diferentes tipos de saberes (Tabela 02). 
Tabela 02 - Características da implementação nas escolas selecionadas

\begin{tabular}{|l|l|l|l|}
\hline Escola/PP & PP & Destinatários/as & $\begin{array}{l}\text { Tipo de saberes que } \\
\text { promovem }\end{array}$ \\
\hline Escola N & $\begin{array}{l}\text { Estágios } \\
\text { Empreendedorismo } \\
\text { Cursos } \\
\text { Orientação vocacional }\end{array}$ & $\begin{array}{l}\text { Todos/as } \\
\text { Todos/as } \\
\text { Todos/as } \\
\text { Todos/as }\end{array}$ & $\begin{array}{l}\text { Técnicos, sociais, } \\
\text { disciplinares }\end{array}$ \\
\hline Escola A & $\begin{array}{l}\text { PDP } \\
\text { Extensão } \\
\text { Estágio }\end{array}$ & $\begin{array}{l}\text { Todos/as } \\
\text { Todos/as } \\
\text { Todos/as (dentro da } \\
\text { escola ou fora) }\end{array}$ & $\begin{array}{l}\text { Técnicos, } \\
\text { disciplinares, sociais }\end{array}$ \\
\hline Escola I & Estágio & $\begin{array}{l}\text { Seletivo conforme } \\
\text { critérios de seleção } \\
\text { Optativo conforme } \\
\text { interessados }\end{array}$ & $\begin{array}{l}\text { Técnicos } \\
\text { Sociais } \\
\text { Disciplinares }\end{array}$ \\
\hline
\end{tabular}

Fonte: elaboração própria

Com respeito à implementação das PP nas escolas analisadas, da Escola $\mathrm{N}$ se pode sintetizar, em primeiro lugar, que a instituição promove uma variedade de dispositivos de formação para o trabalho (cursos especiais, estágios, empreendedorismo, orientação vocacional) que, em nossa opinião, podem ser enquadrados como PP. No entanto, os níveis de institucionalização destas propostas variam conforme os casos. Dos enumerados, só a realização de empreendimentos é um projeto curricular, enquanto que o resto são projetos institucionais que inclusive em vários casos não estão formalizados em texto escrito; alguns deles são mantidos por docentes ad honorem, outros dependem de financiamentos externos para sua realização. A pesar disto, se mantem ano a ano, de modo que se pode propor uma institucionalização informal, mas cristalizada no tempo.

Por outro lado, cabe destacar que todos/as os/as alunos/as participam nestes dispositivos de formação para o trabalho, produzindo uma democratização das práticas que supõe que a oportunidade de participação e de formação seja para todos/as. Assim, a totalidade dos/as alunos/as são capacitados/as em saberes técnicos das especialidades, em saberes genéricos referidos à realização de empreendimentos e em conteúdos concretos segundo as propostas que realizam e em disposições pessoais, ao mesmo tempo em que todos/as adquirem experiências laborais (autônomas nos empreendimentos e em relação de dependência nos estágios), de maneira que, além da riqueza da formação, geram antecedentes laborais. Em termos de Charlot (2008) estamos falando de saberes técnicos, sociais e pessoais. 
Isto supõe, por sua vez, o cumprimento de normativa vigente referida à implementação de práticas profissionalizantes para todos/as os/as estudantes, trabalhada na terceira seção. No entanto, é preciso esclarecer que a implementação destas práticas é previa à sanção da legislação provincial, e resulta então uma escola que, na prática, se adiantou nas normas que, a posteriori, regulamentaram ativação. Além disso, a planificação de alguns dispositivos em função dos interesses vocacionais dos/as jovens, incide positivamente em suas trajetórias post-egresso e na construção dos projetos vitais dos/as alunos/as. Finalmente, a delimitação educativa na perspectiva da Economia Social propõe um vínculo com o mundo do trabalho que supera o ajuste da formação para a inserção laboral num emprego, como também se vincula a uma perspectiva de trabalho em um sentido filosófico, que, por sua vez, habilita outros mundos possíveis (SENNETT, 2009).

Da Escola A, por sua vez, destacamos que, desde o $1^{\circ}$ ano, a proposta educativa se baseia na articulação entre teoria e prática, e analisamos três dispositivos de formação para o trabalho: o projeto Didático-Produtivo, o projeto de extensão rural e o projeto de estágios. Os três são espaços curriculares, de maneira tal que a escola apresenta um elevado grau de institucionalização da proposta educativa, que supõe sua continuidade, mas além dos recursos econômicos e humanos com que conte num momento concreto. Ademais, isto se afasta das maneiras históricas em que se implementou a articulação educação-trabalho nas escolas secundárias argentinas, propondo variações importantes com respeito às escolas técnicas tradicionais, que se caracterizam por dispositivos delimitados e seletivos. Esta institucionalização implica que todos os estudantes participam dos três projetos, por este motivo se tornam instâncias democráticas dos saberes que ali se promovem e circulam. Por sua vez, esta obrigatoriedade supõe que a escola responda à legislação atual que regula as PP. Cabe esclarecer que esta proposta formativa antecede a normativa vigente que a posteriori a enquadra. Efetivamente, os atores escolares "fazem" as políticas significando e ressignificando com suas biografias profissionais num contexto situado (BALL et al., 2012).

A Escola I, por último, realiza estágios no marco das práticas profissionalizantes. Apesar de se desenvolverem faz vários anos, a falta de reconhecimento formal e de remuneração do cargo da professora que se encarrega de realizá-lo gera uma baixa institucionalidade da prática. Ademais, como destacamos, participam somente alguns/as estudantes, selecionados/as por critérios meritocráticos e de requisitos das empresas.

Por isso, este dispositivo é seletivo e meritocrático e se configura como opção, onde a igualdade de oportunidades não é similar a todos os alunos. As práticas constituem 
experiencias desiguais e, portanto, diferenciadoras, construindo nas trajetórias estudantis diferentes oportunidades e modos de aproximação ao mundo do trabalho.

Além disso, destacamos a falta de reconhecimento como PP do projeto de ciclomecânica desenvolvido por atores da sociedade civil, que propõe um vínculo com o mundo do trabalho alternativo ao capitalismo, ancorado no comunitário. Isto mostra que a concepção de trabalho que predomina nesta escola é a do emprego (NEFFA, 2003), vinculada à inserção laboral em empresas privadas em relação de dependência.

Cabe destacar que, ao momento de realizar o campo nesta instituição (2017), a regulamentação vigente não pautava que todos/as os/as alunos/as deviam realizar PP (situação que foi regulamentada em 2018), de maneira que a escola oferecia estágios em função das vagas nas empresas receptoras, limitadas em comparação com a quantidade de estudantes em condições de realizá-las.

\section{Considerações finais}

Desta análise se desprende que há múltiplas maneiras de resolver a articulação entre a escola secundária e o mundo do trabalho que propõe a normativa, que é resolvida pelas escolas em função de suas histórias institucionais, dos recursos, das concepções sobre trabalho e sobre a articulação teoria-prática que mantêm e que, por sua vez, constroem por meio da implementação das PP.

A democratização das práticas implica em promover a possibilidade de que todos/os os/as alunos/as tenham experiências situadas em âmbitos de trabalho que permitem aprender distintos tipos de saberes (CHARLOT, 2008), tais como questões técnicas, de relações de trabalho, de habilidades brandas, de empreendedorismo, etc. Democratização que implica em repensar nos dispositivos que se desenvolvem e nos/as destinatários/as dos mesmos. Nos casos apresentados, ainda que os três desenvolvam diversos dispositivos, não são sempre para todos os alunos. Ou seja, analisamos o que as experiências promovem, ao mesmo tempo que o alcance que se propõe enquanto inclusão de todos/as ou uma seleção meritocrática.

Por outro lado, se desenvolvem ideias do mundo do trabalho diferentes nas três escolas. A Escola $\mathrm{N}$ inclui formação sobre economia social, propondo a todos/as seus alunos/as a elaboração de empreendimentos produtivos dentro da escola como principal PP, e oferecendo a realização de estágios fora da instituição a todos/as. A Escola A também gera propostas ao interior da instituição para todos/as os/as jovens, especialmente a partir do PDP, mas ao resguardo das condições do mercado, já que os/as estudantes realizam 
empreendimentos produtivos dentro da escola, e a ênfase está posta no social e técnico, o que implica na realização de um projeto grupal. Por último, a Escola I oferece estágios só a uns/as poucos/as estudantes para que circulem por espaços reais de trabalho, passando a ser estas PP restritas e meritocráticas.

Ou seja, ainda que as três escolas promovam a realização de PP, são diferentes as experiências que geram, os saberes que estão em jogo e os sentidos do mundo do trabalho que transmitem. Assim, destacamos que na Escola I, se prioriza um olhar do trabalho enquanto emprego, pelo contrário, nas outras poderia se propor o trabalho como atividade produtiva transformadora, ou seja, no sentido que retomamos de Neffa (2003) e Sennett (2009). Então, postulamos que existem diversos modos de articulação com a comunidade (Escola $\mathrm{N}$ e Escola A), como propostas educativas vinculadas com as demandas próprias do mundo do trabalho (Escola I). Nisto encontramos que as leis e resoluções geram um marco a partir do qual as instituições disputam os sentidos tanto do mundo do trabalho que propiciam, como experiências democráticas orientadas à inclusão. Também estas práticas situadas às vezes se dão em contextos reais de trabalho e outras dentro das instituições educativas, o que mostra que o que a legislação habilita é ocupado pelas propostas institucionais com criatividade, novos alcances e limitações.

Finalmente, entendemos que as instituições geram propostas além das leis que as regulam. Em tal sentido, colocada em ação, a política supõe a tradução dos textos da política em ações e práticas situadas (BALL, 2012), nas que se disputam sentidos sobre a escola, sua formação e seu vínculo com o mundo do trabalho. Nestas práticas analisadas se jogam diferentes tipos de saberes (CHARLOT, 2008) e formação, que supõe e habilitam construções de mundos diferentes que tensionam olhares desde a autogestão-agência-comunidade a emprego-mercantilismo-mundo laboral. Se nos situamos na ideia de construir democracia desde as polícias e neste caso concreto, desde os dispositivos de formação para o trabalho nestas escolas, podemos dizer que são diferentes as contribuições de cada uma, adquirindo maior relevância nesta construção as práticas educativas que dão possibilidade de escolher e de participar a todos/os os/as estudantes e que concebem ao trabalho desde uma perspectiva ampla, desde seu papel na construção e transformação social, daqueles que mantêm práticas meritocráticas ou formam para empregos específicos.

Acreditamos que as escolas secundárias encontram desafios em termos políticos, já que as propostas de ensino que geram podem promover a construção de um mundo mais justo e democrático ou aprofundar as desigualdades sociais. Neste leque de possibilidades das 
escolas, o Estado regula por meio de suas normativas e as propostas educativas se constituem num campo de disputas de sentidos.

\section{REFERÊNCIAS}

AGUilar VillanueVA, L. Problemas públicos y Agenda de gobierno. 1. ed. México: Miguel Angel Porrúa, 1993.

ANDRADE MARTINS, E. O papel da educação escolar na construção de conhecimento em tempos de domínio do mercado. RPGE- Revista on line de Política e Gestão Educacional, Araraquara, v. 22, n. 1, p. 322-335, jan./abr. 2018.

ARGENTINA. Decreto Nacional 340, de 24 de febrero de 1992. Régimen de Pasantías para todo el Sistema Educativo Nacional. Ministerio de Justicia y Derechos Humanos, Presidencia de la Nación, ciudad de Buenos Aires, 24 de febrero de 1992. Disponível em:

http://fediap.com.ar/administracion/pdfs/PasantiasenlaFormacionTecnicoProfesional.pdf. Acesso em: 5 fev. 2020.

ARGENTINA. Ley de Educación Técnico Profesional n. 25058, promulgada por el Senado y la cámara de Diputados. Buenos Aires, Argentina, 8 set. 2005. Disponível em: www.inet.edu.ar/wp-content/uploads/2012/10/ley-26058.pdf. Acesso em: 5 fev. 2020.

ARGENTINA. Resolución 261 del Consejo Federal de Educación, del 22 de mayo de 2006. Ministerio de Educación, Ciencia y Tecnología, Consejo Federal de Educación. Buenos Aires, Argentina, 22 maio 2006. Disponível em: http://www.inet.edu.ar/wpcontent/uploads/2012/10/261-06.pdf. Acesso em: 5 fev. 2020.

ARGENTINA. Ley de Educación Nacional n. 26.206, sancionada por el Senado y la cámara de Diputados. Buenos Aires, Argentina, 14 dez. 2006. Disponível em:

http://www.inet.edu.ar/index.php/institucional/normativa/ley-de-educacion-nacional/. Acesso em: 5 fev. 2020.

ARGENTINA. Decreto 1374 del 7 de septiembre de 2011. Aprueba el régimen general de pasantías para todo el ámbito de la educación secundaria del sistema educativo nacional. Ministerio de Justicia y Derechos Humanos, Presidencia de la Nación, ciudad de Buenos Aires, 7 set. 2011. Disponível em:

http://servicios.infoleg.gob.ar/infolegInternet/anexos/185000-189999/186933/norma.htm. Acesso em: 5 fev. 2020.

ARGENTINA. Ley Orgánica de Educación Provincial N²945 de 16 de diciembre de 2014. Legislatura Provincial, cámara de diputados de la Provincia de Neuquén, Neuquén, 16 dez. 2014. Disponível em: www.legislaturaneuquen.gob.ar /svrfiles/Neuleg/normaslegales/pdf/LEY2945.pdf. Acesso em: 5 fev. 2020.

ARGENTINA. Resolución N¹862 del Consejo Provincial de Educación, Provincia de Neuquén, Ciudad de Neuquén, 18 dez. 2018, Disponível em:

http://www.empresaescuela.org/legislacion/Resolucion-1862.pdf. Acesso em: 5 fev. 2020. 
BALL, J. S.; MAGUIRE, M.; BRAUM, A.; HOSKINS, K.; PERRYMAN, J. How schools do Policy. Policy enactments in secondary schools. New York: Routledge, 2012.

BARROS, L. y COSTA-RENDERS, E. A formação profissional das juventudes brasileiras: avanços e perspectivas nas interlocuções entre educação e trabalho. RPGE- Revista on line de Política e Gestão Educacional, Araraquara, v. 24, n. 1, p. 189-209, jan./abr. 2020.

CAMILLIONI, A. Prólogo. In: ANIJOVICH, R. Transitar la formación pedagógica. Dispositivos y estrategias. Buenos Aires: Paidós. 2014. 184 p.

CHARLOT, B. La relación con el saber. Elementos para una teoría. Buenos Aires: Libros del Zorzal. 2008.

CORROCHANO, M. C. Jovens no ensino médio: qual o lugar do trabalho? In: DAYRELL, J.; CARRANO, P.; LINHAREA MAIA, C. (Orgs.). Juventude e ensino médio. Diálogo, sujeitos, currículos. Belo Horizonte: Editora UFMG, 2014. 339 p.

DURSI, C. Nuevos vínculos entre escuelas técnicas y el mundo productivo: experiencias en el sector de la construcción. Novedades Educativas, Buenos Aires, n. 306, p. 15-18, jun. 2016.

FERNÁNDEZ, N. La puesta en acto de las políticas educativas referidas a la educación y al trabajo en el nivel secundario técnico: el papel de los actores involucrados (Estado, sector empresarial y comunidad educativa) en la Provincia de Neuquén. Tesis (Doctorado en Educación) - Universidad Nacional del Comahue, s/d.

FIGARI, C. (Dir.). La trama del capital. La hegemonía empresaria en la Argentina. Buenos Aires: Ed. Biblos, 2017.

GALLART, M. A. La escuela técnica industrial en Argentina. ¿Un modelo para armar? Montevideo: Cinterfor-OIT, 2006.

GALLART, M. A. Veinte años de educación y trabajo. La investigación de la formación y la formación de una investigadora. Montevideo: Cinterfor/OIT, 2002.

GARINO, D. Escuela secundaria y trabajo: incidencias de los dispositivos de formación para el trabajo en las trayectorias laborales de jóvenes en la ciudad de Neuquén. 2017. Tesis (Doctorado en Ciencias Sociales) - Universidad de Buenos Aires, 2017.

GOROSTIAGA, J. La reforma de la educación secundaria argentina en el contexto de América Latina. In: MÁS ROCHA, S. M; GROSTIAGA, J.; TELLO, C.; PINI, M. (Comps.). La educación secundaria como derecho. Buenos Aires: La Crujía. 2012. 328 p.

JACINTO, C. De los derechos a las garantías en las transiciones de los jóvenes al empleo. Alcances y límites de las tramas entre educación secundaria, formación para el trabajo y protección social. In: JACINTO, C. (Coord.). Protección social y formación para el trabajo de jóvenes en la Argentina reciente. Entramados, alcances y tensiones. Buenos Aires: IDES. 2016. $196 \mathrm{p}$. 
JACINTO, C. La formación para el trabajo en la escuela secundaria como reflexión crítica y como recurso. In: MARTINEZ, S. (comp.). Conversaciones en la escuela secundaria. Política, trabajo y subjetividad. General Roca: PubliFadecs. 2018. 524 p.

JACINTO, C.; DURSI, C. La socialización laboral en cuestión: las pasantías ante las incertidumbres de las transiciones laborales de los jóvenes. In: JACINTO, C. (Comp.). La construcción social de las trayectorias laborales de jóvenes. Políticas, instituciones, dispositivos y subjetividades. Buenos Aires: Teseo-IDES. 2010. 400 p.

MATINEZ, S. Dispositivos de formación para el trabajo y la experiencia escolar en la escuela secundaria técnica. Estudio de casos. 2016. Tesis (Doctorado en Educación) Universidad de Buenos Aires, 2016.

MATURO, Y. La escuela técnica y la pasantía en empresas. Aspectos generales sobre su puesta en acto y sus efectos en las expectativas laborales de los alumnos. Praxis educativa, La Pampa, v. 22, n. 1, p. 40-50, 2018.

MATURO, Y; FERNÁNDEZ, N; GANEM, M; SAEZ, D. Las prácticas profesionalizantes en la escuela técnica: aproximaciones comparadas entre Córdoba, Neuquén y Río negro. In: CONGRESO IBEROAMERICANO DE PEDAGOGÍA, 8., 2018, Buenos Aires. Anais [...]. Buenos Aires, ago. 2018.

MONTES, N. La educación secundaria en la región y en el país: dinámica de la expansión y problemáticas que persisten. In: MARTINEZ, S. (Comp.). Conversaciones en la escuela secundaria. Política, trabajo y subjetividad. General Roca: PubliFadecs. 2018. 524 p.

NEFFA, J. El trabajo humano. Contribuciones al estudio de un valor que permanece. Buenos Aires: Lumen Hvmanitas. 2003. 279 p.

RODRIGO, L. La escuela secundaria técnica en Argentina. Un análisis histórico y comparado de las políticas educativas para el sector durante las últimas décadas. In: CONGRESO NACIONAL DE ESTUDIOS COMPARADOS EN EDUCACIÓN, 6., 2017, Buenos Aires. Anais [...]. Buenos Aires: OEI, 2017.

SENNETT, R. El artesano. Barcelona: Anagrama. 2009.

VIOR, S.; MAS ROCHA, S. Nueva Legislación educacional ¿nueva política? In: VIOR, S.; MISURACA, M.; MAS ROCHA, S. (Comps.). Formación de docentes ¿qué cambió después de los '90 en las políticas, los currículos y las instituciones? Buenos Aires: Jorge Baudino Ediciones, 2009. 285 p. 


\section{Como referenciar este artigo}

MARTINEZ, S.; GARINO, D.; FERNANDEZ, N. Escola secundária e formação para o trabalho na Argentina: políticas e saberes em disputa. Revista on line de Política e Gestão Educacional, Araraquara, v. 24, n. esp. 1, p. 841-864, ago. 2020. e-ISSN:1519-9029. DOI: https://doi.org/10.22633/rpge.v24iesp1.13778

Submetido em: 20/02/2020

Revisões requeridas: 30/04/2020

Aprovado em: 28/06/2020

Publicado em: 01/08/2020 